\title{
Astaxanthin - King of antioxidants as immune modulator and anti-inflammatory for enhancing productive performance and health of animals
}

\author{
SV Singh, Yallappa M Somagond and Aditya Deshpande
}

Received: 10 December 2020 / Accepted: 28 December 2020 / Published online: 28 February 2021

(C) Indian Dairy Association (India) 2021

\begin{abstract}
Astaxanthin is the potent antioxidant predominantly found in living organisms that are present in marine environment. It is known as "King of antioxidant" or "Super vitamin E" because of its potent antioxidant property. Antioxidant property of astaxanthin known to modulate different biological activity relating to antioxidant defence system, inflammation, immunity and ameliorating adverse effect of oxidative stress during summer season. Its use has been found in improving both male and female reproductive health and production performance of bovines. Astaxanthin helps in hastening of sexual maturity, improving sperm quality, increasing fertility and better development of embryos. It is considered as one of the essential feed additive in combating the adverse effect of climate change on production performance of animals. This review mainly focuses on source, structure and use of astaxanthin as an antioxidant, antiinflammatory, immune stimulator and for improving productive performance of bovines.
\end{abstract}

Keywords: Astaxanthin, Bovines, Heat stress, Immunity, Inflammation

\section{Introduction}

Antioxidants are "free-radical scavengers" that can evade slow damage to cells caused by free radicals, which are produced in body as a reaction to environmental and other stresses. In the animals, carotenoids are considered as part of the antioxidant defence system. Carotenoids are pigment that plays an essential role in mitigating oxidative processes. They are potent antioxidants that can scavenge mono-molecular oxygen and peroxyl radicals. They influence cellular signalling and activate

Animal Physiology Division, ICAR-National Dairy Research Institute, Karnal-132 001, India

S V Singh $(\bowtie)$

Animal Physiology Division, ICAR-National Dairy Research Institute, Karnal-132 001, India

Email:sohanvir2011@gmail.com) redox sensitive controlling pathways (Stahl and Sies, 2005). High concentration of carotenoids is commonly found in plants, algae and microorganisms. Animals and humans do not synthesis these carotenoids, therefore its necessary to provide them in diet (Sandmann, 1994). Carotenoids acts by inhibiting chain reaction by taking out free radicals, as these carotenoids contain polyene chain and long double bonds they perform as potent antioxidant.

Astaxanthin is considered one of the strongest carotenoids which is capable of protecting cells, lipids and membranes lipoproteins from oxidative damage (Naguib, 2000). This review mainly focuses on source, structure and use of astaxanthin as an antioxidant, anti-inflammatory, immune stimulator and reproductive health of bovines.

\section{Sources of astaxanthin (Ast)}

Astaxanthin is predominantly found in organisms that are present in marine environment i.e. in microalgae, plankton, krill and seafood and also present in yeast, fungi, complex plants and the feathers of some birds (flamingos and quail) (Hussein et al. 2006). Astaxanthin was previously extracted from krill (Euphausia superba) (Takaichi et al. 2003) and recently from green algae (Haematococcus pluvialis) or red yeast (Phaffia rhodozyma) by various cultivation methods which help to obtain pure astaxanthin (Ambati, 2014) Astaxanthin obtained from algae are two times more effective as compared to synthetic astaxanthin (Guerin, 2001). Haematococcus pluvialis is a green microalga that builds up high levels of astaxanthine in stress environment like high salinity, deficiency of nitrogen content, high temperature and light (Choi et al. 2002). It is regarded as the foremost source of natural astaxanthin. Holtin et al. (2009) reported that Haematococcus pluvialis comprises approximately $4 \%$ of free form, $2 \%$ of diester type and $94 \%$ of monoester type.

\section{Structure of astaxanthin}

Astaxanthin consists of special molecular structure on each ionone ring, i.e. presence of hydroxyl and keto molecules, which are accountable for the potent antioxidant properties and superior position in the membrane (Liu and Osawa, 2007). Astaxanthin comprises conjugated double bonds, hydroxyl and keto groups 
(Figure 1). It has both lipophilic and hydrophilic properties (Higuera-Ciapara et al. 2006). Astaxanthin has two oxygenated groups on each ring structure that are responsible for its increased antioxidant characteristics (Guerin et al. 2003). In general lipid soluble antioxidants protects lipid soluble part of cells and watersoluble antioxidants protect the water-soluble portion of cells, but the unique structure of astaxanthin enables it to extend throughout cell membrane to play both roles and provides the cell membrane stability. Astaxanthin's polyene chain traps radicals in the cell membrane, while the astaxanthin terminal ring can scavenge radicals on the inner and outer parts of the cell membrane (Miki, 1991).

Naturally astaxanthin occurs in different forms (Table 1) esterified and free form and as isomers (Higuera-Ciapara et al. 2006). Synthetic astaxanthin is a molecule similar to that formed in living organisms and consists of a mixture of isomers 1:2:1 (3S, 3S), (3R, $3 \mathrm{~S})$, and (3R, 3R), respectively.

\section{Mechanism of action of astaxanthin}

Astaxanthin helps in neutralizing free radicals (nitrogen, sulphur, carbon and oxygen free radical) either by donating electrons to unpaired electrons or by quenching of unpaired electrons. Astaxanthin binds with free radical to form unreactive compound and help in quenching electron out of membrane (Figure 2) and resisting it from converting into pro-oxidant molecule.

\section{Pharmacokinetics of Astaxanthin}

Astaxanthin is carotenoid xanthophyll compound, is absorbed into body comparable to lipids and conveyed via lymphatic system (Figure 3). It get incorporated with lipoproteins and reaches tissues (Rao et al. 2013). Astaxanthin is a fat soluble compound, with enhanced absorption when supplemented along oils in diet. Absorption of astaxanthin also depends on associated dietary components. Bioavailability of astaxanthin in humans was improved when given with lipid-based diets, high levels of carotenes gets solubilized in the oil phase of the food matrix which can lead to better absorption (Olson, 2004; Rao et al. 2013). Lara et al. (2007) also stated that combination of astaxanthin and fish oil showed summative effect which contributed to improved immune response in wistar rats.

\section{Biological Activity of Astaxanthin}

Astaxanthin exhibited higher bioactivity than other antioxidants, since it could attach from inside to outside with cell membrane (Yuan et al. 2011). Astaxanthin is used as a nutrient in aquatic animals and as a pigmentation of broilers and egg yolk in the poultry industry (Cyanotech, 2000). Astaxanthin products are used as tablets, capsules, syrups, oils, soft gels, creams, biomass and granular powders for commercial applications in nutraceuticals. It acts as potent antioxidant, used as a dietary supplement to treat cardiovascular and neurodegenerative

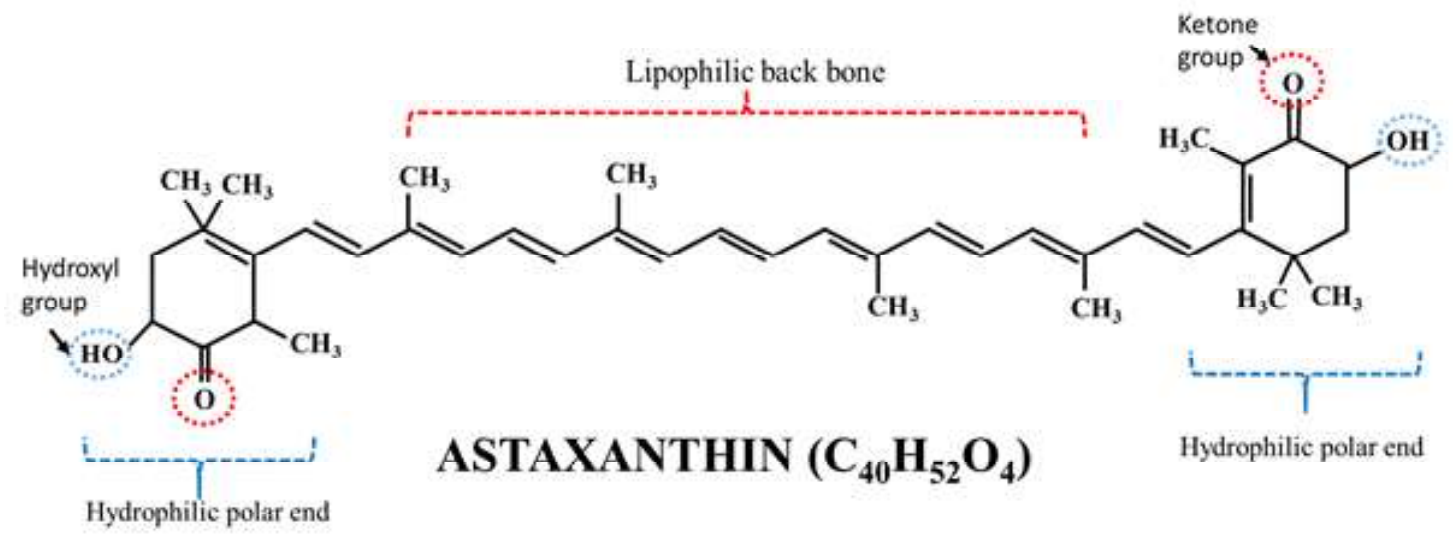

Fig. 1 Chemical structure of Astaxanthin, Molecular formula $-\mathrm{C}_{40} \mathrm{H}_{52} \mathrm{O}_{4}$ and Molar mass - $596.84 \mathrm{~g} / \mathrm{mol}$ (Higuera-Ciapara et al. 2006)

Role of astaxanthin in molecular system (Biswal, 2014)

\begin{tabular}{lc}
\hline Quenching of singlet oxygen & Reduces free radical concentration \\
\hline Removing of radicals & Prevent chain reactions \\
Inhibiting lipid peroxidation & Membrane structure is maintained \\
Regulation of gene expression & Improvement of immune system \\
Acts as COX-2 inhibitor & Reduces inflammation \\
Inhibits enzyme activity of iNOS & Reduces nitric oxide level \\
Reduces C-reactive protein (CRP), & Decreases systemic inflammation \\
Suppresses inflammatory gene expression & Subduing of NF-kappa Beta activation and I(kappa)B \\
Suppresses inflammatory agents & Prostaglandin E2, IL-10, TNFalfa \\
Anti-androgen effects & Inhibition of enzyme 5-a-reductase \\
\hline
\end{tabular}




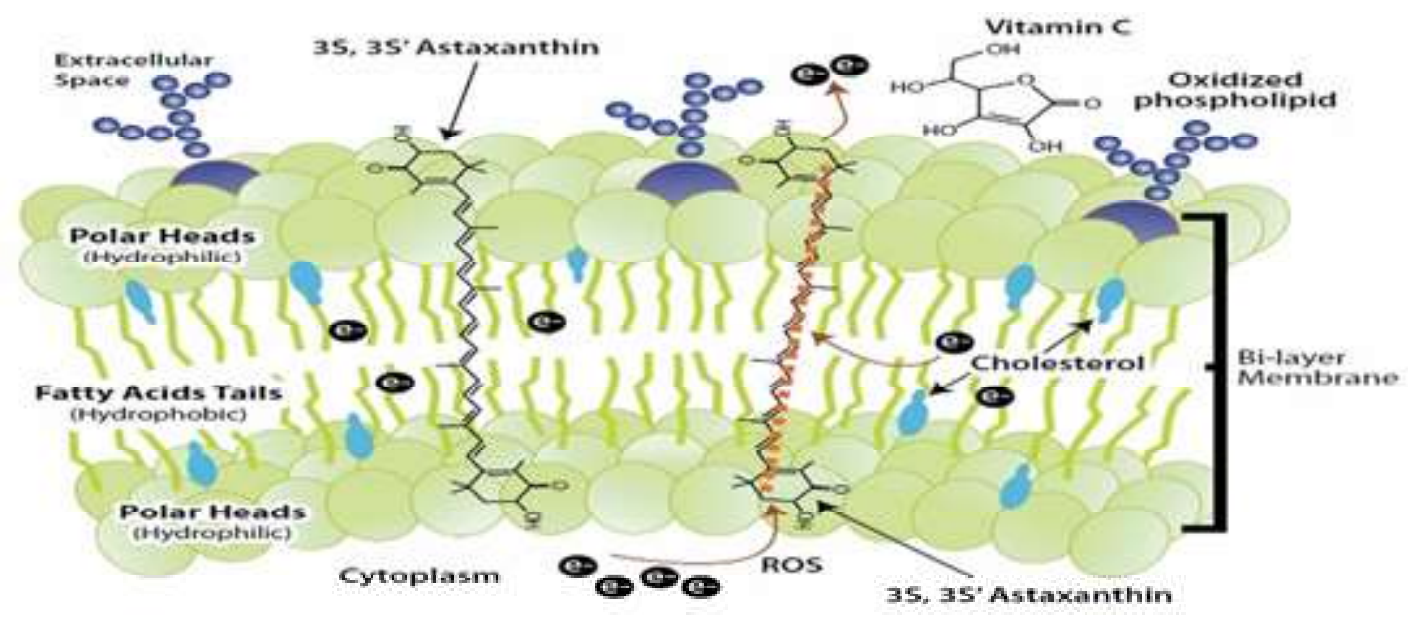

Fig. 2: Presence of astaxanthin in cell membrane (Pashkow et al. 2008)

Table 1 Different forms of astaxanthin

\begin{tabular}{|c|c|}
\hline Source of astaxanthin & Different forms \\
\hline Antarctic krill (Euphausia superba) & $3 \mathrm{R}, 32 \mathrm{R}$ - occurs as the este \\
\hline Wild Atlantic salmon & $3 \mathrm{~S}, 32 \mathrm{~S}$ occurs as the free $\mathrm{f}$ \\
\hline Haematococcus pluvialis & $(3 \mathrm{~S}, 32 \mathrm{~S})$ - occurs as the ste \\
\hline $\begin{array}{l}\text { Xanthophyllomyces } \\
\text { dendrorhous }\end{array}$ & $(3 R, 32 R)$ - occurs as the st \\
\hline
\end{tabular}

\section{Astaxanthin as a potent antioxidant}

Astaxanthin is known as "king of carotenoids" or "supervitamin E" (Pan et al. 2003). It is having both direct and indirect antioxidant actions. Directly scavenges free oxygen radicals to stop chain reactions involved in oxidative damage and indirectly activates enzymes of antioxidant defence system (Buesen et al. 2015). Astaxanthin's ability to penetrate biological membranes with a defensive effect of lipid peroxidation within and outside of the cell membrane is one of its main features (Goto et al. 2001). Antioxidant strength of astaxanthin is 10 times more than zeaxanthin, lutein, canthaxanthin, $\beta$-carotene and 100 times greater than $\alpha$-tocopherol and reported that many of carotenoid antioxidants like lycopene and zeaxanthin, or vitamins $\mathrm{C}$ and $\mathrm{E}$ under certain conditions become pro-oxidants but astaxnthin never turns into a pro-oxidant (Miki, 1991). Several in- vitro (Speranza et al. 2012) and in-vivo studies (Lee et al. 2011; Augusti et al. 2012) demonstrated antioxidant activity of astaxanthin.

Astaxanthin increases the activity of antioxidant enzymes (SOD, Catalase, GPx) considerably in astaxanthin treated LS- 180 cell line (Hormozi et al. 2019) and in rats supplemented with astaxanthin orally (Rao et al. 2013). Yang (2011) reported that astaxanthin is capable of restoring the activity of non-enzymatic antioxidants such as GSH, vitamins $\mathrm{C}$ and $\mathrm{E}$ and other antioxidant enzymes. Dietary supplementation of astaxanthin can provide antioxidant protection for cells and used in preventing atherosclerotic cardiovascular disease (Pashkow et al. 2008). It is considered as one of the potent antioxidant, as it increases the activity antioxidant enzymes (Choi et al. 2002). Increased expression of caspase 3 and Bax, which showed its antiproliferative effects in the LS-180 cell line (Tang et al. 2018; Hormozi et al. 2019). Astaxanthin enhances liver function, upturns the potential for defence against oxidative stress and influences on mechanisms of biodefense significantly (Amar et al. 2001).

Astaxanthin has been used as dietary supplement in ameliorating adverse effect of oxidative stress in bovines in hot humid and hot dry season. Beneficial impact of astaxanthin supplementing in murrah buffaloes (Priyadarshini, 2017) and in Tharparkar and Karan Fries heifers (Kumar, 2018) helped to preventing adverse effects of summer stress and improved antioxidant defence system during the summer season. Higher levels of TAC in astaxanthin supplemented heifers helped in reducing the generation of singlet radicals during oxidative stress conditions. Decreased levels of TBARS and lipid peroxidation in treatment group indicated decreased levels of stress in heifers and potent antioxidant activity of astaxnthin in heifers (Kumar and Singh, 2020). Astaxanthin is able to ameliorate adverse effects of oxidative stress in lactating buffaloes by decreasing cortisol and other stress markers in supplemented group (Somagond et al. 2019). Dietary supplementation of astaxanthin during harsh climatic conditions makes animals more heat tolerant and resilient. 
Table 2 Use of astaxanthin in bovines

\begin{tabular}{|c|c|c|c|}
\hline Animal & Dosage & Effects of astaxanthin & Reference \\
\hline $\begin{array}{ll}\text { Karan } & \text { Fries } \\
\text { bulls } & \end{array}$ & $\begin{array}{l}0.25 \mathrm{mg} / \mathrm{kg} \\
\mathrm{BW} / \text { day/animal }\end{array}$ & $\begin{array}{l}\text { Improved the semen quality during } \\
\text { summer season }\end{array}$ & $\begin{array}{l}\text { Soren et al. (2017) } \\
\text { Soren and Singh (2018) }\end{array}$ \\
\hline $\begin{array}{l}\text { Pregnant } \\
\text { dairy cows }\end{array}$ & $\begin{array}{l}1 \mathrm{mg} / \mathrm{kg} \text { body } \\
\text { weight }\end{array}$ & - $\quad$ Elevated corpus luteal (CL) function. & Kamada et al. (2017) \\
\hline Murrah & $0.25 \mathrm{mg} / \mathrm{kg}$ & - Inhibited the level of inflammatory & Priyadarshini \\
\hline $\begin{array}{l}\text { buffaloes } \\
\text { (pre and }\end{array}$ & $\mathrm{BW} /$ day/animal & $\begin{array}{l}\begin{array}{l}\text { cytokines by blocking } \mathrm{NF}-\mathrm{\kappa} B \\
\text { activation }\end{array}\end{array}$ & Aggarwal, (2018) \\
\hline $\begin{array}{l}\text { postpartum } \\
\text { Murrah } \\
\text { buffaloes) }\end{array}$ & & $\begin{array}{l}\text { - Improved the milk production } \\
\text { performance of animal }\end{array}$ & \\
\hline $\begin{array}{l}\text { Karan Fries } \\
\text { and } \\
\text { Tharparkar }\end{array}$ & $\begin{array}{l}0.25 \mathrm{mg} / \mathrm{kg} \\
\mathrm{BW} / \text { day/animal }\end{array}$ & $\begin{array}{l}\text { - Higher weight gain and early } \\
\text { attainment of puberty during summer } \\
\text { season }\end{array}$ & Kumar and Singh (2020). \\
\hline heifers & & $\begin{array}{l}\text { - Improved the antioxidant status, } \\
\text { immunity, growth rate and decreased } \\
\text { rate of cell death }\end{array}$ & \\
\hline Lactating & $0.25 \mathrm{mg} / \mathrm{kg}$ & - Increased milk yield by $5.39 \%$ by & Somagond et al. (2019) \\
\hline Murrah & $\mathrm{BW} /$ day/animal & astaxanthin supplementation alone & and Somagond et al. \\
\hline Buffaloes & & $\begin{array}{l}\text { and } 15.6 \% \text { by combination of } \\
\text { astaxanthin }+ \text { prill fat } \\
\text { Reduced physiological responses and } \\
\text { stress indicators levels during summer } \\
\text { stress }\end{array}$ & $(2020)$ \\
\hline
\end{tabular}

\section{Anti-inflammatory and immunomodulatory action of astaxanthin}

Astaxanthin is an effective antioxidant for terminating inflammation in biological systems. Several studies reported that astaxanthin mainly of marine origin showed its potent antioxidant and anti-inflammatory action (Fassett and Coombes, 2011). There was significant decrease in infection and gastric inflammatory conditions in H. pylori-infected mice when they are treated with algal cell extracts containing astaxanthin (Liu and Lee, 2003). Anti-inflammatory effects of astaxanthin shown through through inhibiting the expression genes like inducible NO synthase (iNOS), cyclooxygenase-2, tumor necrosis factor-alpha (TNFalpha), and interleukin-1beta (IL-1beta) involved in proinflammatory and blocking of NF-kappa B activation and reduced inflammatory mediators. Treatment with astaxanthin helps in reducing the secretion of pro-inflammatory cytokines from NF$\kappa \mathrm{B}$ transcription factor by $\mathrm{ROS}$ induced production in $\mathrm{H}_{2} \mathrm{O}_{2}$ stimulated mononuclear U937 cells (Speranza et al. 2012).

Astaxanthin is also involved in decreasing expression of $\mathrm{Bcl} 2$ genes and increases the expression of Caspase 3 and Bax genes, thereby, inhibiting the cells growth and proliferation and inducing apoptosis of cancer cells. So it was said that astaxanthin is also involved treating and prevention of cancers and strengthening the immune system in humans (Pashkow et al. 2008). Similarly Priyadarshini and Aggarwal (2018) reported dietary

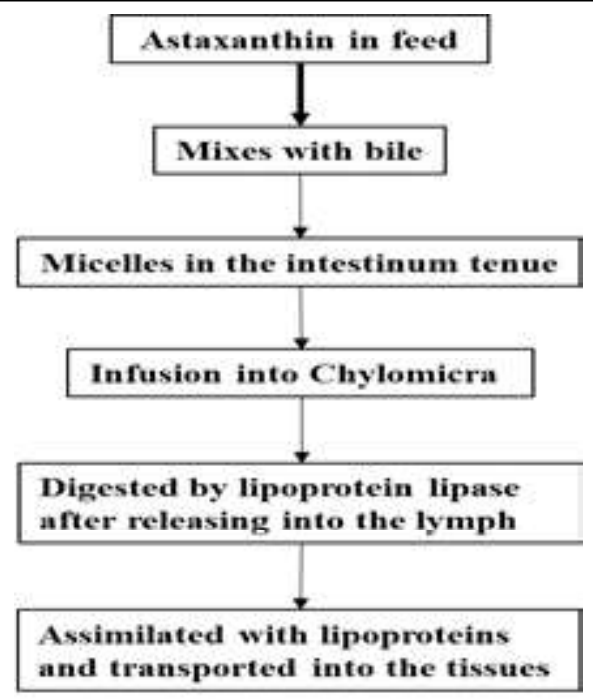

Fig. 3 Pharmacokinetics of astaxanthin (Olson, 2004)

supplementation of astaxnthin in Murrah buffaloes prevented expression of genes involved in pro-inflammatory reactions, as a result of suppressing activation of $\mathrm{NF} \mathrm{kB}$ and decreased level of inflammatory mediators. Kumar and Singh (2019) revealed that impact of heat stress was ameliorated in Karan Fries and Tharparkar heifers through NF- $\mathrm{B}$ down regulation, which regulated the expression of genes involved in inflammatory reactions and quenching of free radicals. There were lower 
cortisol levels in astaxanthin supplemented groups which showed heat stress alleviation effect during summer season.

In contrast to $\beta$-carotene and vitamin $\mathrm{E}$, astaxanthin displayed greater immunomodulatory effects in mouse model (Jyonouchi, 1991). Studies in crustaceans, mainly on shrimp astaxanthin helped in improving immune response and increases tolerance to stress (Darachai et al. 1999). Dietary supplementation of astaxanthin increased antibody production and helped in restoring humoral immune response in older mice (Jyonouchi, 1991). Park et al. (2010) reported that astaxanthin acts as antiviral agent which is involved in enhancing natural killer cells activity, there by destroying virus infected cells. Dietary supplementation of astaxanthin in Murrah buffaloes increased the amount of IgG levels, which could neutralise reactive oxygen species and protected immune cells from lipid peroxidation (Priyadarshini and Aggarwal, 2018).

\section{Astaxanthin in reproductive health of animals}

\section{Effect on female reproduction}

Despite the fact that astaxanthin is solemnly used for pigmentation and as potent antioxidant, it has many other uses relating to reproduction in fish, i.e., hastening of sexual maturity, improvement in fertilization, survival of eggs and better development of embryos (Putman, 1992). Negative effects of heat stress on in vitro embryo production in summer season can be ameliorated by dietary supplementation of astaxanthin. It helps in restoring reproductive performance of dairy cows exposed to heat stress through regulation oxygen free radicals and antioxidant enzymes in oocytes and cumulus-oocyte complexes (Ispada et al. 2018). Young et al. (1995) described that by dietary supplementation of astaxanthin derived from Haematococcus pluvialis was sufficient to elicit its antioxidant effect by detoxification of accumulated peroxides and improving ovary functions. Dietary supplementation of astaxanthin showed increase in corpora lutea (CL), implant sites and foetuses, thereby, decreasing abortion in Minks (Hansen et al. 2001). The addition of astaxanthin to the culture medium help in development of early bovine embryos in culture medium by ameliorating adverse effect of heat stress. In addition, astaxanthin promotes embryonic development during heat stress condition by altering expression genes related to stress (SHC1 and SOD2) (Namekawa et al. 2010). Addition of astaxanthin to maturation medium $(0.5 \mathrm{ppm})$ improved growth and maturation of porcine oocyte and also increased the number of oocytes reaching metaphase II and considerably reduced apoptosis of oocytes exposed to $\mathrm{H}_{2} \mathrm{O}_{2}$ during in vitro maturation (IVM) (Do et al. 2015). Jang et al. (2010) revealed that addition of astaxanthin enhanced the growth of cultured embryos in bovine oviduct epithelial cells. Kuroki et al. (2013) also reported that astaxanthin supplementation during IVM enhanced mitochondrial membrane potential, which can help in rescuing oocyte from ROS generated due to heat induction.

\section{Effect on male reproduction}

In astaxanthin supplemented group of goldfish (Carassius auratus), higher sperm motility and fertilization rate was reported by Tizkar et al. (2015). Astaxanthin supplementation to human patient showed positive effect on sperm cells by decreasing the ROS and secretion of inhibin B, hence improving sperm quality and its function and increased conception rates or fertility (Comhaire, 2005). Concentrations of $2 \mu \mathrm{M}$ and $4 \mu \mathrm{M}$ of astaxanthin appeared to be successful dose to increase sperm potency during oxidative stress conditions (Salamon and Maxwell, 2000). Astaxanthin treatment in male mice greatly improved weight of testis and sperm morphological characteristics. Astaxanthin was able to restore sperm DNA damage because of generation of ROS in Cyclophosphamide (CP) induced toxicity. It also indicated germ cell protection of astaxanthin against chemo toxicity (Tripathi and Jena, 2008). Astaxanthin fed rats have shown a substantial reduction in ROS production in semen and improved male fertility (Mortazavi et al. 2014). Semen extender added with astaxanthin helped in improving the sperm quality and function of ram by reducing of malondialdehyde and ROS during storage (Fang et al. 2015) and bull (Farzan et al. 2014, Soren et al. 2017) semen at $5{ }^{\circ} \mathrm{C}$ for 72 hours. During production of miniature pig semen straw, adding of astaxanthin to frozen storage solutions, prevented damages during freeze-thawing process and maintained quality of sperms and improved fertility rate (Lee and Kim, 2018).

Kumar and Singh (2020) revealed that dietary supplementation of astaxanthin to Karan Fries and Sahiwal heifers helped in increasing level of growth hormone $(\mathrm{GH})$, conservation of energy, increased growth performance and early attainment of puberty in supplemented group. Holstein bulls supplemented with astaxanthin enhanced the sperm progressive motility and reduced the lipid peroxidation rate in semen (Farzan et al. 2014). Addition of astaxanthin $(0.25 \mathrm{mg} / \mathrm{kg}$ body weight) revealed low level of antioxidant enzymes in semen, indicating positive effect on semen quality in Karan Fries bulls in heat stress conditions (Soren et al. 2017). Dietary Supplementation of astaxanthin in summer to crossbred (Karan Fries) bulls improved the quality of semen by improving antioxidant activity, which was indicated by decreased malondialdehyde concentration and higher expression of mitochondrial gene in spermatozoa like, mitochondrial transcriptions factor A (TFAM), citrate synthases (CS) and succinate dehydrogenase (SDH),. Supplementation with astaxanthin also enhanced semen quality parameters (volume, motility, concentration, and acrosome integrity) and reduced major abnormalities in semen over non supplemented bulls. Therefore, astaxanthin supplementation can be used as one of strategies in improving semen quality of crossbred bulls and amelioration of adverse effect of heat stress was suggested by Soren and Singh (2018). 
Astaxanthin which acts as a potent antioxidant helps in amelioration of adverse effect of heat stress and improving productive performance of animals. Kumar and Singh (2020) reported astaxanthin supplementation in diets of heifers helped in improvement of growth, immunity, which subsequently leads to early attainment of puberty and increased productive life of cattle. Astaxanthin supplementation along with prill fat was able to maintain body condition and health status of buffaloes by mitigating adverse effect during summer season (Somagond et al. 2020). Priyadarshni (2017) revealed that astaxanthin supplementation enhanced immunity and lowered stress marker levels in Murrah buffaloes and improved reproductive health and milk yield by $7 \%$ during heat stress condition. There was $5.39 \%$ and $15.6 \%$ increase in milk yield in astaxanthin and astaxanthin in combination with prill fat fed groups of buffaloes over control group, respectively during summer season (Somagond et al. 2019).

\section{Conclusion}

Astaxanthin as a feed additive helps in amelioration of adverse effects of heat stress, acts as anti-inflammatory, improves immunity, reduces stress levels in bovines. Therefore, astaxanthin can be used as an important feed additive to combat the adverse effect of climate change/ stress and for improving production performance of animals during adverse climatic conditions.

\section{References}

Amar EC, Kiron V, Satoh S, Watanabe T (2001) Influence of various dietary synthetic carotenoids on bio defence mechanisms in rainbow trout, Oncorhynchus mykiss (Walbaum). Aquac Res 32: 162-173

Ambati RR, Phang SM, Ravi S, Aswathanarayana, RG (2014) Astaxanthin: sources, extraction, stability, biological activities and its commercial applications - a review. Mar Drugs 12: 128-152

Augusti PR, Quatrin A, Somacal S, Conterato GM, Sobieski R, Ruviaro AR, and Emanuelli T (2012) Astaxanthin prevents changes in the activities of thioredoxin reductase and paraoxonase in hypercholesterolemic rabbits. J Clin Biochem Nutr 51: 42-49

Biswal S (2014) Oxidative stress and astaxanthin: The novel supernutrient carotenoid. Int J Res Health Allied Sci 3: 147

Buesen R, Schulte S, Strauss V, Treumann S, Becker M, Groters S, Van Ravenzwaay B (2015) Safety assessment of [3S, 32 S]-astaxanthinSubchronic toxicity study in rats. Food Chem Toxicol 81:129-136

Choi YE, Yun YS, Park JM (2002) Evaluation of factors promoting astaxanthin production by a unicellular green alga, Haematococcus pluvialis, with fractional factorial design. Biotechnol Prog 18: 11701175

Comhaire FH, Garem YE, Mahmoud A, Eertmans F, Schoonjans FRANK (2005) Combined conventional/antioxidant "Astaxanthin" treatment for male infertility: a double blind, randomized trial. Asian J Androl 7: 257-262

Cyanotech 2000 NatuRose ${ }^{\circledR}$. Available at www.cyanotech.com/ html/asta/ natu/naturose.html [accessed 12 December 2007]

Darachai J, Piyatiratitivorakul S, Menasveta P (1999) Effect of astaxanthin on growth and survival of Penaeus monodon larvae. In Proceedings of the 37th Kasetsart University Annual Conference 36-41

Do LTK, Luu VV, Morita Y, Taniguchi M, Nii M, Peter AT, Otoi T (2015) Astaxanthin present in the maturation medium reduces negative effects of heat shock on the developmental competence of porcine oocytes. Reprod Biol 15: 86-93

Fang YI, Zhong R, Chen L, Feng C, Sun H, Zhou D (2015) Effects of astaxanthin supplementation on the sperm quality and antioxidant capacity of ram semen during liquid storage. Small Rumin Res 130: 178-182

Farzan M, Chamani M, Varnaseri H (2014) The antioxidant effect of astaxanthin on quantitative and qualitative parameters of bull sperm. Indian Journal of Foundamental and Applied Life Sciences 4: 425-430

Fassett RG, Coombes JS (2011) Astaxanthin: a potential therapeutic agent in cardiovascular disease. Mar Drugs 9(3): 447-465

Foss P, Renstrøm B, Liaaen-Jensen S (1987) Natural occurrence of enantiomeric and Meso astaxanthin 7"-crustaceans including zooplankton. Comp Biochem Physiol B 86: 313-314

Goto S, Kogure K, Abe K, Kimata Y, Kitahama K, Yamashita E, Terada H (2001) Efficient radical trapping at the surface and inside the phospholipid membrane is responsible for highly potent antiperoxidative activity of the carotenoid astaxanthin. Biochim Biophys Acta Biomembr 1512: 251-258

Guerin M (2001) Pigmentation of red seabream with natural astaxanthin derived from the alga Haematococcus pluvialis: comparison with synthetic astaxanthin. In Aquaculture 2001 conference, Lake Buena Vista, Florida, January 2001. World Aquaculture Society

Guerin M, Huntley ME, Olaizola M (2003) Haematococcus astaxanthin: applications for human health and nutrition. Trends Biotechnol 21: 210-216

Hansen KB, Tauson AH, Inborr J (2001) Effect of supplementation with the antioxidant astaxanthin on reproduction, pre-weaning growth performance of kits and daily milk intake in mink. J Reprod Fertil Suppl 57: 331-334

Higuera-Ciapara I, Felix-Valenzuela L, Goycoolea FM (2006) Astaxanthin: a review of its chemistry and applications. Crit Rev Food Sci Nutr 46: $185-196$

Holtin K, Kuehnle M, Rehbein J, Schuler P, Nicholson G, Albert K (2009) Determination of astaxanthin and astaxanthin esters in the microalgae Haematococcus pluvialis by LC-(APCI) MS and characterization of predominant carotenoid isomers by NMR spectroscopy. Anal Bioanal Chem 395: 1613

Hormozi M, Ghoreishi S, Baharvand P (2019) Astaxanthin induces apoptosis and increases activity of antioxidant enzymes in LS-180 cells. Artif Cells Nanomed Biotechnol 47: 891-895

Hussein G, Sankawa U, Goto H, Matsumoto K, Watanabe H (2006) Astaxanthin, a carotenoid with potential in human health and nutrition. J. Nat. Prod 69: 443-449

Ispada J, Rodrigues TA, Risolia PHB, Lima RS, Gonçalves DR, Rettori D, Paula-Lopes FF (2018) Astaxanthin counteracts the effects of heat shock on the maturation of bovine oocytes. Reprod Fert Dev 30: 1169-1179

Jang HY, Ji S J Kim, YH Lee, HY Shin, JS, Cheong HT, Yang BK (2010) Antioxidative effects of astaxanthin against nitric oxide induced oxidative stress on cell viability and gene expression in bovine oviduct epithelial cell and the developmental competence of bovine IVM/ IVF embryos. Reprod Domest Anim 45: 967-974

Jyonouchi H, Hill RJ, Tomita Y, Good RA (1991) Studies of immunomodulating actions of carotenoids. I. Effects of $\beta$ carotene and astaxanthin on murine lymphocyte functions and cell surface marker expression in in vitro culture system. Nutr Cancer 16: 93105

Kamada H, Akagi S, Watanabe S (2017) Astaxanthin increases progesterone production in cultured bovine luteal cells. J Vet Med Sci 17-0044

Kumar S (2018) Influence of astaxanthin supplementation on growth performance, immunity and antioxidant status in heifers during 
summer season (Doctoral dissertation, National Dairy Research Institute, Karnal)

Kumar S, Singh SV (2019) Inhibition of NF-kB signaling pathway by astaxanthin supplementation for prevention of heat stress-induced inflammatory changes and apoptosis in Karan Fries heifers. Trop Anim Health Pro 51: 1125-1134

Kumar S, Singh SV (2020) Influence of astaxanthin supplementation on attainment of puberty and lipid peroxidation in Sahiwal and Karan Fries (Holstein $\times$ Tharparkar) heifers during summer season. Biol Rhythm Res 51: 15-28

Kuroki T, Ikeda S, Okada T, Maoka T, Kitamura A, Sugimoto M, Kume S (2013) Astaxanthin ameliorates heat stress-induced impairment of blastocyst development In Vitro:-astaxanthin colocalization with and action on mitochondria. J Assist Reprod Gen 30: 623-631

Lara JJ, Economou M, Wallace AM, Rumley A, Lowe G, Slater C, Lean ME (2007) Benefits of salmon eating on traditional and novel vascular risk factors in young, non-obese healthy subjects. Atherosclerosis 193: 213-221

Lee DH, Kim CS, Lee YJ (2011) Astaxanthin protects against MPTP/ $\mathrm{MPP}+$-induced mitochondrial dysfunction and ROS production in vivo and in vitro. "Food Chem. Toxicol 49: 271-280

Lee E, Kim D (2018) Effects of astaxanthin on miniature pig sperm cryopreservation. Biomed Res Int. doi.org/10.1111/and.13389.

Liu BH, Lee YK (2003). Effect of total secondary carotenoids extracts from Chlorococcum sp. on Helicobacter pylori-infected BALB/c mice. Int Immunopharmacol 3: 979-986.

Liu X, Osawa T (2007) Cis astaxanthin and especially 9-cis astaxanthin exhibits a higher antioxidant activity in vitro compared to the alltrans isomer. Biochem Biophys Res Commun 357: 187-193

McNulty H, Jacob RF, Mason RP (2008) Biologic activity of carotenoids related to distinct membrane physicochemical interactions. Am J Cardiol 101: S20-S29

Miki W (1991) Biological functions and activities of animal carotenoids. Pure Appl Chem 63: 141-146

Mortazavi M, Salehi I, Alizadeh Z, Vahabian M and Roushandeh AM (2014) Protective effects of antioxidants on sperm parameters and seminiferous tubules epithelium in high fat-fed rats. J Reprod Infertil 15: 22

Naguib YM (2000) Antioxidant activities of astaxanthin and related carotenoids. J Agric Food Chem 48: 1150-1154

Namekawa T, Ikeda S,Sugimoto M, Kume S (2010) Effects of astaxanthin containing oil on development and stress related gene expression of bovine embryos exposed to heat stress. Reprod Domest Anim 45(6): e387-e391

Olson J A (2004) Carotenoids: absorption, transport, and metabolism of carotenoids in humans. Pure Appl Chem 66: 1011-1016

Pan CH, Chien YH, Hunter B (2003) The resistance to ammonia stress of Penaeus monodon, Fabricius juvenile fed diets supplemented with astaxanthin. J Exp Mar Biol Ecol 297: 107-118

Park JS, Chyun JH, Kim YK, Line LL, Chew BP (2010) Astaxanthin decreased oxidative stress and inflammation and enhanced immune response in humans. Nutr. Metab 7: 18

Pashkow FJ, Watumull DG, Campbell CL (2008) Astaxanthin: a novel potential treatment for oxidative stress and inflammation in cardiovascular disease. Am J Cardiol 101: 58-S68

Priyadarshini L (2017) Immunity, antioxidant, energy status and production performance in pre and post-partum Murrah buffaloes during summer and winter seasons (Doctoral dissertation, National Dairy Research Institute; Karnal)

Priyadarshini L, Aggarwal A (2018) Astaxanthin inhibits cytokines production and inflammatory gene expression by suppressing IкB kinase-dependent nuclear factor $\kappa \mathrm{B}$ activation in pre and postpartum Murrah buffaloes during different seasons. Vet World 11: 782

Putman M (1992) A review of the nature, function, variability, and supply of pigments in salmonid fish. EAS Special Publication

Rao AR, Sindhuja HN, Dharmesh SM, Sankar KU, Sarada R, Ravishankar GA (2013) Effective inhibition of skin cancer, tyrosinase, and antioxidative properties by astaxanthin and astaxanthin esters from the green alga Haematococcus pluvialis. ýJ Agric Food Chem 61: 3842-3851

Salamon S, Maxwell WMC (2000) Storage of ram semen. Anim. Reprod Sci 62: 77-111

Sandmann G (1994) Carotenoid biosynthesis in microorganisms and plants. In EJB Reviews. Springer, Berlin, Heidelberg 129-146

Somagond YM, Singh S, Deshpande A, Sheoran P, Chahal VP (2020) Physiological responses, energy metabolites and prolactin levels of buffaloes supplemented with dietary astaxanthin, prill fat and their combination during heat stress. Indian J Anim Sci 90: 55-60

Somagond YM, Singh SV, Deshpande A (2019) Effect of dietary supplementation of astaxanthin, prill fat and combination on stress indicators, milk yield and composition during heat stress in buffaloes. Biol Rhythm Res 1-11.doi.org/10.1080/ 09291016.2019.1658426

Soren S, Singh SV (2018) Semen quality, lipid peroxidation and expression of mitochondrial gene in ejaculated sperm of Karan Fries (Tharparkar x Holstein Friesian) bulls supplemented with astaxanthin. Indian J Anim Sci 88: 1346-1352

Soren S, Singh SV, Kumar S (2017) Effect of astaxanthin supplementation on semen (Karan Fries Bulls) storage at 5 C. Int J Curr Microbiol Appl Sci 6: 23-28

Speranza, L, Pesce M, Patruno A, Franceschelli S, Lutiis MAD, Grilli A, Felaco M (2012) Astaxanthin treatment reduced oxidative induced pro-inflammatory cytokines secretion in U937: SHP-1 as a novel biological target. Mar Drugs 10: 890-899

Stahl W, Sies H (2005) Bioactivity and protective effects of natural carotenoids. Biochim Biophys Acta Mol Basis Dis 1740: 101-107

Takaichi S, Matsui K, Nakamura M, Muramatsu M, Hanada S (2003) Fatty acids of astaxanthin esters in krill determined by mild mass spectrometry. Comp Biochem Physiol B Biochem Mol Biol 136: 317-322

Tang X, Liu B, Wang X, Yu Q, Fang R (2018) Epidermal growth factor, through alleviating oxidative stress, protect IPEC-J2 cells from lipopolysaccharides-induced apoptosis. Int J Mol Sci 19: 848

Tizkar B, Kazemi R, Alipour A, Seidavi A, Naseralavi G, Ponce-Palafox JT (2015) Effects of dietary supplementation with astaxanthin and $\beta$ carotene on the semen quality of goldfish (Carassius auratus). Theriogenology 84: 1111-1117

Tripathi DN, Jena GB (2008) Astaxanthin inhibits cytotoxic and genotoxic effects of cyclophosphamide in mice germ cells. Toxicology 248: 96-103

Yang Y, Seo JM, Nguyen A, Pham TX, Park HJ, Park Y, Lee J (2011) Astaxanthin-rich extract from the green alga Haematococcus pluvialis lowers plasma lipid concentrations and enhances antioxidant defense in apolipoprotein E knockout mice. J Nutr 141: 1611-1617

Young FM, Luderer WB, Rodgers RJ (1995) The antioxidant $\beta$-carotene prevents covalent cross-linking between cholesterol side-chain cleavage cytochrome P450 and its electron donor, adrenodoxin, in bovine luteal cells. Mol Cell Endocrinol 109: 113-118

Yuan JP, Peng J, Yin K, Wang JH (2011) Potential health promoting effects of astaxanthin: A high value carotenoid mostly from microalgae. Mol Nutr Food Res 55: 150-165 